\title{
REFLEXÕES SOBRE O PERFIL LINGUÍSTICO DE PROFESSORES DE LÍNGUAS EM FORMAÇÃO NO CONTEXTO MULTILÍNGUE DE FOZ DO IGUAÇU
}

\author{
REFLECTIONS ON THE LANGUAGE PROFILE OF \\ PRE-SERVICE LANGUAGE TEACHERS IN THE \\ MULTILINGUAL CONTEXT OF FOZ DO IGUASSU
}

Isis Ribeiro Berger*

Luan Henrique Mendes**

RESumo: Este estudo tematiza o multilinguismo em sala de aula e foi desenvolvido no
campo da Política Linguística. O objetivo é apresentar e discutir o perfil linguístico
de estudantes do Curso de Letras de uma universidade localizada em Foz do Iguaçu,
face à pluralidade linguística e cultural existente no município e região. A metodologia
empregou levantamentos de campo, por meio de pesquisa exploratória realizada entre
2017 e 2018, tendo como referência os mapeamentos linguísticos escolares. O estudo
contribui para a construção de conhecimentos sobre contextos socioeducacionais
plurilíngues e sobre a gestão do multilinguismo na educação, subsidiando reflexões
sobre políticas linguísticas institucionais. A pesquisa tem como pressuposto o de que
o reconhecimento e a sensibilização da comunidade acadêmica quanto à pluralidade
linguística local e regional é fundamental para que ações em torno das línguas na e
da instituição estejam alinhadas ao contexto em que ela se insere.

Palavras-chave: Perfil linguístico; Multilinguismo; Mapeamento linguístico escolar.

ABstract: This study focuses on multilingualism in classrooms and was developed in
the field of Language Policy. The objective is to present and discuss the linguistic profile
of students in the Letters Course at a university located in Foz do Iguaçu, given the
linguistic and cultural plurality existing in the city and region. The methodology used
field surveys, through exploratory research carried out between 2017 and 2018, using
school language mappings as the methodological reference. The study contributes to

\footnotetext{
"Doutora em Linguística (Políticas Linguísticas). Professora Adjunta da Universidade Estadual do Oeste do Paraná Campus Foz do Iguaçu. Docente do Curso de Letras e do Programa de Pós-graduação Sociedade, Cultura e Fronteiras. Membro da Cátedra Unesco em Políticas Linguísticas para o multilinguismo. E-mail: isis.berger@unioeste.br.

" Graduando em Letras - Licenciatura em Português -Inglês e respectivas literaturas pela Universidade Estadual do Oeste do Paraná - Campus Foz do Iguaçu. Bolsista de Iniciação Científica, com bolsa da Fundação Araucária. E-mail: luanhenriquemendes716@gmail.com.
} 
the construction of knowledge about plurilingual socio-educational contexts and the management of multilingualism in education, supporting reflections on institutional language policies. The research presupposes that recognition and sensitization of the academic community regarding local and regional linguistic plurality is essential so that actions around languages at and within the institution are aligned with the context in which it operates.

KeYwords: Linguistic profile; Multilingualism; School language mapping.

\section{CONSIDERAÇõES INICIAIS}

O tema do multilinguismo na escola e na sociedade tem se tornado recorrente nas mais variadas pesquisas no âmbito da Política Linguística no Brasil. De acordo com o site Ethnologue, ${ }^{1}$ maior catálogo de línguas do mundo, existem 7.139 línguas no planeta, um número em constante fluxo devido às transformações que ocorrem no mundo. Segundo Calvet (2002, p. 27), "o mundo é plurilíngue em cada um de seus pontos e que as comunidades linguísticas se margeiam, se superpõem continuamente. O plurilinguismo faz com que as línguas estejam constantemente em contato."

O ambiente linguístico de Foz do Iguaçu, município brasileiro situado na região oeste do Estado do Paraná, na fronteira entre o Brasil e outros dois países hispano-falantes (Paraguai e a Argentina), não é diferente. Trata-se de um município em que se verifica grande pluralidade linguística e cultural, tanto pela sua posição geopolítica na fronteira, como devido aos diversos processos migratórios que se deram nesse espaço geográfico, compondo um mosaico linguístico e cultural peculiar. Foz do Iguaçu é reconhecida, dentre suas muitas características, por abrigar diferentes comunidades linguísticas e de fala que fazem uso, nas relações cotidianas, de línguas diversas, além da língua oficial nacional do Estado Brasileiro (a língua portuguesa), da Língua Brasileira de Sinais, regulamentada em todo território nacional, e de línguas de comunidades indígenas que historicamente compõem o povoamento da região.

Essa pluralidade de línguas de Foz do Iguaçu, que tematiza hoje uma gama de trabalhos acadêmicos, é resultante tanto de sua localização na divisa com dois países que possuem o espanhol/castelhano como língua oficial - sendo um deles, o Paraguai, também bilíngue em uma língua de origem indígena (o guarani) -, bem como de fatores históricos, econômicos e culturais que culminaram na presença de imigrantes (e descendentes) de várias partes do mundo. Destaca-se, ainda, o fato de que o município é polo de turismo internacional, recebendo visitantes de várias partes do mundo, que acrescenta a essa localidade mais um fator de circulação de línguas e, por isso, promove na região uma configuração linguística e cultural notadamente diversa.

${ }^{1}$ Disponível em https://www.ethnologue.com. Acesso em: 30 jul, 2021. 
Nesse espaço geográfico, situam-se duas universidades públicas que impactam no desenvolvimento econômico, educacional e social da região, sendo um dos campi da Universidade Estadual do Oeste do Paraná - UNIOESTE e a Universidade Federal da Integração LatinoAmericana - UNILA, que desde sua fundação no ano de 2010 vem incorporando ainda mais línguas e variedades a esse espaço geográfico, por se constituir de uma comunidade acadêmica multilíngue e multicultural.

Em face à realidade plurilíngue do município e região, o perfil linguístico da comunidade acadêmica de ambas as instituições é notadamente diverso, o que impacta em processos de ensino-aprendizagem e, portanto, na importância do desenvolvimento de políticas linguísticas públicas que voltem o olhar para a especificidade linguística do entorno. Diante dessa assunção, questionamos: Como se caracteriza o perfil sociolinguístico de estudantes do curso de Letras de Foz do Iguaçu, da UNIOESTE, Campus Foz do Iguaçu, diante desse cenário diverso? Qual a relação desses estudantes com as línguas da comunidade e do entorno social?

De modo a responder essas perguntas, desenvolvemos um projeto de pesquisa no âmbito do Grupo de Pesquisa em Políticas Linguísticas e Educacionais no Oeste do Paraná com o objetivo de mapear as línguas que compõem os repertórios linguísticos desse grupo em específico, bem como depreender suas possíveis relações com diferentes línguas. Partimos da premissa de que é importante que os Cursos de Letras, voltados aos estudos da linguagem, formem profissionais para a região que possam refletir e agir criticamente diante da pluralidade linguístico-cultural do entorno social e que, para tanto, um passo inicial consiste no reconhecimento e sensibilização quanto ao seu próprio perfil sociolinguístico (MENKEN; GARCÍA, 2010).

A pesquisa se justificou diante do fato de que não havia, até então, um levantamento dessas informações no âmbito do curso no campus de Foz do Iguaçu, o que, de certo modo, reflete uma orientação monolíngue que por longo tempo permeou os saberes historicamente construídos sobre as línguas no país e, por conseguinte, nos domínios das escolas e espaços de ensino-aprendizagem. Nesse sentido, volvemos à Fraga (2014) quando ressalta que professores-formadores trabalham em classes em que nem todos os alunos nasceram em um mesmo país e não compartilham da mesma herança linguístico-cultural e étnica. Isso é uma constante nessa região de fronteira.

Assim, diante dessas colocações, esse estudo teve como objetivo realizar um levantamento inicial do perfil linguístico desse alunado, compreender as relações estabelecidas entre os estudantes e as línguas em coexistência no município, bem como depreender se (e de que forma) a presença dessas diversas línguas refletem nas relações e práticas linguísticas cotidianas, precisamente nas trocas interculturais. Assim, tivemos como proposta a de que esse estudo contribuísse para a construção de conhecimentos sobre contextos educacionais sociolinguisticamente complexos, bem como tecer reflexões em torno do multi/plurilinguismo na formação de professores de línguas, de modo a subsidiar reflexões que contribuam com 
políticas linguísticas institucionais para a valorização e promoção da pluralidade linguística local e regional.

Temos como pressuposto que o reconhecimento e sensibilização da comunidade acadêmica quanto à pluralidade linguística local e regional deve se constituir como fundamental para que as ações em torno das línguas na e da instituição estejam alinhadas ao contexto em que a instituição se insere. Esse texto, portanto, dialoga com a Política Linguística Institucional da universidade, em que consta um dos importantes objetivos e valores da instituição, no que diz respeito à valorização da diversidade linguística e cultural local, a saber:

[...] contribuir para o fortalecimento das pesquisas e ações em torno das políticas linguísticas voltadas para contextos de multilinguismo, em que se incluem o fomento às políticas linguístico-educacionais públicas e políticas de promoção da diversidade e da valorização do patrimônio linguístico-cultural de diversas comunidades, visando ao desenvolvimento sustentável, por meio de ações que visem à salvaguarda de línguas e culturas (UNIOESTE, 2018, p. 4).

No que tange à metodologia, a investigação se caracterizou como pesquisa exploratória, em que realizamos levantamento do perfil linguístico de professores em formação, nos anos de 2017 e 2018. Adotamos como referência a metodologia do mapeamento linguístico escolar (BROCH, 2014) e pressupostos dos diagnósticos sociolinguísticos descritos por Seiffert (2014), como instrumentos político-linguísticos para a promoção de pluralidade de línguas. Assim, neste artigo, apresentamos e discutimos os resultados obtidos nessa pesquisa, os quais contribuem para a visibilidade, em espaços de educação formal, das muitas línguas que coexistem e que tornam Foz do Iguaçu uma cidade linguisticamente diversa, constituída por inúmeras culturas.

No que se refere à organização deste texto, na primeira seção discutimos a questão dos desafios para as políticas linguísticas educacionais no que tange ao multilinguismo no domínio da escola (e da universidade). Na seção posterior, expomos a metodologia da investigação e prosseguimos com a apresentação e análise dos dados, em que tecemos reflexões e considerações em torno do perfil linguístico dos professores em formação. Por fim, tecemos nossas conclusões.

\section{O MULTILINGUisMo EM SALA DE AULA E AS POLÍTICAS LINGUÍSTICAS}

Os espaços educacionais são, por natureza, ambientes em que se encontram a diversidade de culturas, de saberes, de modos de ser e de estar no mundo, e de línguas. Por longo tempo na história do Brasil, políticas de homogeneização linguística em favor da língua portuguesa (OLIVEIRA, 2009; OLIVEIRA; ALTENHOFEN, 2011) como representativa de uma cultura 
nacional, bem como políticas de ensino de língua estrangeira inclinadas a uma homogeneização linguística às avessas no currículo escolar em favor da língua inglesa foram centrais para o estabelecimento de uma cultura linguística no país. Hoje, no entanto, verificamos um outro movimento diante do multilinguismo, que lança o olhar sobre o fenômeno como um recurso importantíssimo para o desenvolvimento de sociedades sustentáveis.

Os múltiplos deslocamentos populacionais em várias direções e entre fronteiras, bem como o fluxo de informações e serviços em diferentes línguas face às recentes tendências da globalização no século XXI vêm impactando no cenário linguístico-cultural de vários países (GARCÍA, 2009). Isso incide diretamente na emergência de diferentes orientações político-linguísticas diante da pluralidade linguística em diversos países do mundo, levando à mudança de perspectiva em relação à presença e uso de várias línguas nos territórios nacionais. O reconhecimento da pluralidade linguística passa a figurar no rol da proteção de direitos linguísticos fundamentais como patrimônio cultural imaterial.

Nesse enquadre, discursos diante da pluralidade linguística como patrimônio da humanidade e como potencial recurso para sociedades democráticas e sustentáveis vêm se instaurando e são sustentados por organismos e agências internacionais, a exemplo da UNESCO (Organização das Nações Unidas para a Educação, a Ciência e a Cultura). Portanto, a abertura para as línguas em diversos espaços sociais vem incidindo na construção de outros saberes, políticas e práticas. Por ocasião do Dia Internacional do Letramento, em 09 de setembro de 2019, a Unesco alertou para a importância de os países repensarem o letramento em contextos multilíngues como elemento essencial para lidar com os desafios do letramento global e encorajou a comunidade internacional a investir em políticas e práticas que refletissem as necessidades e entorno social dos estudantes, de modo a fomentar a pluralidade linguística e a inclusão na educação (UNESCO, 2019). Acrescenta-se, ainda, a nota conceitual da UNESCO pelo Dia Internacional da Língua Materna, em 21 de fevereiro de 2021, em que o fomento ao multilinguismo é tratado como fundamental para a inclusão na sociedade e na educação, com a meta de "não deixar ninguém para trás" nos processos de ensino-aprendizagem e integração social (UNESCO, 2021).

No que tange ao lugar do multilinguismo na escola, Broch (2014, p. 33) postula que afirmar que a escola é um espaço para a pluralidade de línguas e de culturas pode parecer óbvio, porém a pesquisadora analisa que "[...] a prática mostra que este espaço não está aberto a todas as línguas e variedades, principalmente quando se trata de línguas minoritárias ou de baixo prestígio". No Brasil, no senso comum, embora afirmar 'ser bilíngue' implique em admiração, até com um certo fetiche, ao analisarmos mais detalhadamente o que está implícito nessa atitude linguística muito comumente percebida na sociedade, verificamos que não se trata de uma valorização daquele(s) que manejam duas ou mais línguas, ou seja de uma valorização do bilinguismo societal. Diferentemente, percebemos que se trata de uma valorização em relação àqueles que conhecem e usam línguas consideradas de prestígio, mais precisamente o inglês 
no contexto da atualidade. Conforme Oliveira e Altenhofen (2011, p. 190), o bilinguismo societal vivo, como o que verificamos em contextos de fronteira ou em áreas bi ou plurilíngues de imigração, por exemplo, "[...] apesar de equivaler à meta educacional do ensino de línguas, não é reconhecido e aplaudido na mesma medida, como um ideal a ser preservado e fomentado."

Em contextos de fronteira, o transitar por entre os limites dos territórios nacionais, assim como o transitar entre línguas, é uma constante no cotidiano das vivências e práticas linguísticas. Desse modo, não raro encontramos indivíduos cujos repertórios linguísticos se caracterizam pela multiplicidade de línguas e de distintas habilidades nessas línguas, adquiridas em situações cotidianas, às vezes muito antes de aprenderem (algumas delas) formalmente no domínio da escola. Citando Berger (2015, p. 69-70): "São pessoas que independentemente da escolarização e desde a socialização primária, estão expostas ao uso regular e alternante de duas ou mais línguas nos diversos espaços sociais.".

O ambiente sociolinguístico multilíngue do entorno social incide diretamente nas interações que se dão nos espaços de ensino-aprendizagem, pois as línguas que compõem os repertórios linguísticos dos alunos e professores constituem-se de base para performarem significados e identidades. Por isso, políticas linguístico-educacionais essencialmente monolíngues, que não levam em conta as demandas linguísticas próprias do século XXI, bem como aquelas próprias de contextos de fronteira, por exemplo, podem ser consideradas inadequadas num cenário em que as migrações se intensificam, em que comunidades falantes de línguas minoritárias clamam por seus direitos de uso e salvaguarda de suas línguas em diversos espaços sociais e, por fim, em um cenário em que cada vez mais as línguas desempenham um lugar de destaque na sociedade do conhecimento (OLIVEIRA, 2010).

Diante dessas considerações, podemos afirmar que os espaços de ensino-aprendizagem se constituem como locus profícuo à implementação de políticas linguístico-educacionais que articulem espaços para o reconhecimento, valorização e promoção do multilinguismo, pois "as políticas linguísticas educacionais fornecem uma estrutura ou texto que envolvem os educadores em comportamentos situados em seus próprios contextos locais." (GARCÍA; MENKEN, 2010, p. 256, tradução nossa). Ainda, segundo Spolsky (2009), o domínio da escola é crucial para a implementação de políticas linguísticas, pois é na escola que o aluno receberá a influência de seus professores (agentes de gestão de línguas) em relação às suas práticas e atitudes linguísticas. ${ }^{2}$

Nesse sentido, vale mencionar também o artigo 23, da Declaração Universal dos Direitos Linguísticos, que pontua que "3. A educação deve estar sempre ao serviço da diversidade

\footnotetext{
${ }^{2}$ Definimos atitudes linguísticas como "[...] a predisposição para pensar, sentir e agir diante de determinadas línguas, variedades ou grupos linguísticos". Dito de outro modo, trata-se de "fenômeno multifacetado que se relaciona à manutenção ou desaparecimento de algumas línguas, à forma como os estatutos das línguas são atribuídos e convencionados social e politicamente, às posições que as tantas línguas do mundo ocupam no tecido social frente relações de poder, às políticas linguísticas implícitas e explícitas, bem como à maneira como diversas comunidades de fala e linguísticas falam de e sobre suas línguas". (BERGER, 2020, p. 4).
} 
linguística e cultural, e das relações harmoniosas entre as diferentes comunidades linguísticas do mundo inteiro." (OLIVEIRA, 2003).

Ampliando nosso olhar para o domínio da universidade, em que se dá a formação inicial de professores de línguas, ou seja, de profissionais que precisam necessariamente perceber a configuração do ambiente sociolinguístico em que se dará seu exercício profissional, compreendermos o importante papel da instituição em prover os subsídios teórico-metodológicos em torno dessa problemática, bem como desenvolver ações de pesquisa e extensão, necessários para que os futuros profissionais tenham as condições fundamentais para posicionarem-se e agirem diante dos desafios que contextos multilíngues apresentam. Conforme Heck et al. (2020, p. 154), a formação de professores "[...] é um poderoso instrumento (ou mecanismo) de política linguística e educacional, uma vez que determinará e/ou influenciará sobre suas crenças, ideologias, práticas pedagógicas e tomadas de decisões adequadas sobre as línguas e seus usos na sociedade".

De posse dessas considerações, passamos para a abordagem dos procedimentos metodológicos adotados para a realização desta pesquisa, seguindo com a apresentação dos dados e reflexões sobre o perfil linguístico de professores de línguas em formação da UNIOESTE, no contexto multilíngue de Foz do Iguaçu.

\section{O MAPEAMENTO DO PERFIL LINGUÍSTICO DE PROFESSORES DE LETRAS EM FORMAÇÃo}

\section{PROCEDIMENTOS METODOLÓGICOS}

Esta pesquisa teve como objetivos mapear o perfil linguístico de acadêmicos do Curso de Letras, bem como depreender que possíveis relações esses participantes estabelecem com as línguas do entorno social, considerando o contexto em que se situa a universidade. Tratouse de uma pesquisa do tipo exploratória (GIL, 2011), visando proporcionar uma visão geral sobre o fenômeno do multilinguismo presente na sala de aula do referido curso de graduação.

De modo a alcançar os objetivos propostos, desenvolvemos um levantamento de campo em que interrogamos os participantes da pesquisa diretamente, por meio de questionário misto, o que nos permitiu a geração de dados quantitativos e qualitativos. Os questionários foram desenvolvidos tendo como referência a metodologia do Mapeamento Linguístico Escolar (doravante MLE) apresentada por Broch (2014), cujos instrumentos de pesquisa permitem conhecer o contexto sociolinguístico da instituição de ensino.

Também consideramos as reflexões de Seiffert (2014) a respeito dos diagnósticos sociolinguísticos como instrumentos político-linguísticos para a promoção do multilinguismo. Nesse sentido, os diagnósticos consistem em instrumentos de pesquisa sociolinguística, visando compreender uma problemática ou questão relacionada a situações de contatos linguísticos 
com vistas à proposição de intervenções em termos de políticas linguísticas, configurando-se como instrumentos de pesquisa interdisciplinares, desde sua construção a critérios de análise e sistematização dos dados que podem ter viés quantitativo e qualitativo.

O questionário foi composto de 10 (dez) perguntas e foi aplicado nos anos de 2017-2018, entre uma amostra de 100 participantes, formada de acadêmicos do $1^{\circ}$ ao $4^{\circ}$ ano do Curso de Letras com dupla habilitação em Português e Inglês/Espanhol. A amostra continha em igual proporção acadêmicos de ambos os cursos. As questões propostas tinham como objetivos: 1) conhecer as línguas que compunham os repertórios linguísticos do público alvo, em diferentes níveis de habilidades, buscando identificar, assim, seus conhecimentos em outras línguas além do português; 2) identificar que línguas declaravam como primeira(s) língua(s) e suas razões para essa escolha; 3) identificar as línguas por eles faladas e usadas em casa, buscando depreender se o domínio familiar se caracterizava como um ambiente multilíngue; 4) identificar as línguas com as quais os acadêmicos mais se identificavam, para depreender suas possíveis relações com diversas línguas; e, por fim, 5) identificar as línguas que os acadêmicos desejavam aprender, além daquelas contidas na grade do curso de graduação, buscando conhecer, assim, valores por eles atribuídos às línguas.

De posse dos dados, foi-nos possível realizar reflexões quanto ao perfil linguístico dessa comunidade frente ao contexto plural e multilíngue em meio à realidade linguística da cidade de Foz do Iguaçu (PR), conforme passaremos a expor na seção seguinte.

\section{APRESENTAÇÃO E DISCUSSÃO DOS RESULTADOS}

Consoante Menken e García (2010), diante da pluralidade linguístico e cultural que caracteriza o ambiente sociolinguístico em que se inserem os espaços instrucionais, faz-se necessário identificar, sistematicamente, o perfil linguístico da comunidade escolar, por meio de diagnósticos e de práticas pedagógicas. Esse é um princípio importante para que seja possível a proposição de ações e políticas linguísticas adequadas ao contexto multilíngue de ensino-aprendizagem.

De posse desse pressuposto, a questão central de nosso instrumento de pesquisa teve como finalidade conhecer quais línguas compunham os repertórios dos acadêmicos do Curso de Letras, nossos professores em formação. Essa questão foi elaborada a fim de que os participantes tivessem a possibilidade de marcar diferentes línguas e em diferentes habilidades. Para tanto, informamos aos participantes que eles poderiam marcar as habilidades linguísticas (fala, compreende, escreve e lê), independentemente de seus diferentes níveis de conhecimento (básico, intermediário ou avançado). Isso porque partimos da premissa de que repertórios linguísticos plurais podem ser constituídos de elementos de diversas línguas, em diversos níveis, aprendidos e adquiridos em uma gama de contextos de uso e para fins diversos (GARCÍA, 2009). Nesse sentido, concordamos também com Savedra (2009, p. 122) quando propõe que a 
condição de "ser bilíngue" é um "fenômeno relativo" que pode assumir "diferentes contornos de competência linguística e comunicativa”.

No que tange às línguas constantes da listagem da pergunta, o critério utilizado para apresentar as opções de línguas na questão, além daquelas que são oficiais e/ou nacionais no Brasil e nos países vizinhos, foi o da presença de comunidades de fala dessas línguas no entorno social. Indicamos também a opção 'outra', para o caso de não termos contemplado alguma das línguas que pudesse constituir os repertórios dos participantes.

Adicionalmente, de modo a tratar qualitativamente os dados quantitativos, incluímos outras questões para que pudessem comentar e prover mais detalhes sobre seus repertórios linguísticos e sobre as línguas indicadas, bem como sobre suas possíveis relações com as línguas, conforme explicitamos na subseção anterior. A seguir, na Tabela 1, apresentamos a sistematização dos dados encontrados e, paralelamente, apresentamos alguns dos comentários feitos pelos participantes. ${ }^{3}$

Tabela 1 - Línguas constantes no repertório linguístico dos professores em formação

\begin{tabular}{|l|c|c|c|c|}
\hline \multicolumn{2}{c}{ Fala } & Compreende & Escreve & Lê \\
\hline Alemão & 4 & 5 & 2 & 3 \\
\hline Árabe & 1 & 2 & 1 & 1 \\
\hline Chinês & 1 & 2 & 1 & 1 \\
\hline Espanhol/Castelhano & 55 & 87 & 50 & 72 \\
\hline Francês & 8 & 12 & 9 & 11 \\
\hline Guarani & 7 & 8 & 4 & 4 \\
\hline Inglês & 63 & 74 & 66 & 70 \\
\hline Italiano & 3 & 6 & 3 & 6 \\
\hline Japonês & 3 & 4 & 3 & 4 \\
\hline LIBRAS & 6 & 8 & & \\
\hline
\end{tabular}

Fonte: Dados da pesquisa. Elaboração dos autores.

Os resultados indicaram que a maioria dos participantes possuem habilidades em outras línguas, além do português (língua oficial nacional do Estado Brasileiro), mais precisamente, em sua maioria, em espanhol e em inglês. Considerando o fato de que o curso provê dupla habilitação em língua portuguesa e inglês/espanhol, os dados quantitativos em relação a essas línguas foram, de certo modo, esperados, já que o ensino formal dessas línguas faz parte da grade curricular dos cursos. Nesse sentido, verificamos que a habilidade de compreensão oral (ou gestual visual no caso de LIBRAS) se destaca entre as demais e isso se caracterizou como um padrão para todas as línguas assinaladas.

Com relação à LIBRAS, língua oficialmente regulamentada em todo o território nacional brasileiro, verificamos que alguns dos participantes declararam possuir habilidades no

\footnotetext{
${ }^{3}$ Para fins de padronização, utilizaremos a letra P para o comentário do participante, seguida de numeração em ordem crescente de apresentação.
} 
idioma. Ressalta-se, nesse sentido, que nossa amostra contou com participantes ouvintes, o que nos leva a avaliar positivamente a presença de falantes de LIBRAS entre eles. Conforme verificamos por meio das questões abertas, a indicação dessa língua por 8 (oito) dos participantes resultou principalmente de aulas ofertadas no curso de graduação e em cursos livres ofertados por instituições religiosas e associações locais. Além disso, ao analisar os dados qualitativos, identificamos que 01 (um) participante possuía uma experiência prévia de contato com familiar surda, o que proporcionou uma comunicação mais eficiente, conforme se lê nos comentários a seguir:

PI: "[...] tenho contato desde criança pois tenho uma irmã surda, mas só aprendi realmente a língua [LIBRAS] a partir de 2014 com um curso de intérprete fornecido pela igreja que frequento."

P2: "[...] desde que aprendi LIBRAS melhorou muito o contato com a minha irmã."

Com relação ao espanhol/castelhano, embora a língua se constitua como parte da formação daqueles que cursam dupla habilitação Português/Espanhol, buscamos compreender os dados qualitativamente no sentido de identificar de que modo a situação geopolítica do município, na fronteira entre dois países hispano-falantes, influenciava os repertórios dos participantes na sua totalidade.

Conforme apresentamos na Tabela 1, identificamos um número elevado de participantes que declaram possuir diferentes habilidades nessa língua, sendo mais expressivas as habilidades de leitura (72 participantes) e compreensão (87 participantes). Tendo em vista que a universidade se situa nesse espaço de encontro entre línguas e culturas de dois países hispano-falantes, além do fato de alguns alunos serem oriundos do Paraguai, os dados evidenciam os efeitos do multilinguismo social no dia-a-dia e na vivência dos participantes, que possivelmente interagem com essa língua em suas relações cotidianas em diferentes domínios. Ou seja, se levarmos em conta que, durante a pesquisa, a maioria dos participantes afirmaram ter nascido e vivido na região de tríplice fronteira pela maior parte de sua vida, podemos concluir que o contato com o espanhol em contexto fronteiriço entre Argentina, Brasil e Paraguai se reflete inevitavelmente nos repertórios linguísticos da maioria deles. Os comentários a seguir lançam luz a essa questão:

P3: "Compreendo um pouco de espanhol por estar em um contexto de fronteira."

P4: "Eu tenho mais contatos com essas línguas [português e espanhol/ castelhano], ou seja, questão de nacionalidade e fronteira."

P5: "Eu cresci na tríplice fronteira, portanto, eu adquiri essas três línguas em casa [Castellano, guarani y português], pela televisão, no convívio mesmo. Entendendo essa adquirição como uma ação inconsciente." 
P6: "Eu gosto do idioma [Espanhol] e em área de fronteira o contato com falantes dessa língua é inevitável.”

Desse modo, analisamos que estar na fronteira impacta necessariamente nas relações dos estudantes com as línguas, o que confirma o argumento de García (2009) de que em ambientes intensamente multilíngues é quase impossível comunicar-se sem ser afetado pela experiência do plurilinguismo e que, por isso, as salas de aula, sendo espaços sociais, devem incluir as línguas da comunidade e as práticas linguísticas locais em suas ações cotidianas. Por essa razão, consideramos que professores em formação precisam ser capazes de refletir e agir criticamente face à essa realidade, cujos espaços educacionais e sociais são permeados por estudantes que possuem repertórios linguísticos dos mais diversos. Conforme Lunardelli e Santos (2020, p. 53), "[...] a escola pode ser considerada um cenário estratégico para a implementação de políticas linguísticas [inclusivas], por ser lugar de transformação de comportamentos.”.

Direcionamos então nossa atenção à língua guarani, uma das línguas oficiais do Estado Paraguaio, que possui origem indígena e é falada majoritariamente por uma população não-indígena no país. Em nossos dados, entre os 100 participantes que contribuíram com essa pesquisa, 8 (oito) deles declararam compreender guarani e 7 (sete), falar guarani. Ao cotejar os dados qualitativos e quantitativos, verificamos que 05 (cinco) participantes nasceram no Paraguai, o que, de certo modo, nos informa sobre alguma situação de contato com as línguas desse país, bem como sobre os movimentos circulares que se dão em região de fronteira. Entre os comentários, um dos participantes destacou a relação de afeto com a língua, que se caracteriza como herança familiar:

P7: “A aquisição do guarani foi maternalmente. Minha avó materna só se comunicava conosco em guarani."

No que tange à situação sociolinguística do Paraguai, cabe ressaltar que do contato entre guarani e espanhol/castelhano emerge o jopará, uma "terceira língua paraguaia" que, para diferentes estudiosos, pode ser compreendida como uma castelhanização do guarani, ou seja, um contínuo entre as duas línguas majoritárias do país: a do colonizador (espanhol) e a da resistência (o guarani) (SANTOS, 2020). Trazer à tona essa questão nos é relevante porque, embora não tenhamos inserido o jopará entre as opções a serem marcadas na primeira questão, a menção ao jopará sobressai em nossos dados qualitativos em que um dos participantes explica o seguinte:

P8: “Ao [marcar] guarani me refiro ao jopará já que a maioria só fala desta forma no Paraguai."

Conforme mencionamos, as línguas apresentadas na Tabela 1 foram indicadas no questionário seguindo o critério da existência de múltiplas comunidades de fala de diferentes línguas no ambiente sociolinguístico do entorno. De posse das respostas, pudermos 
verificar que línguas como alemão, árabe, chinês, crioulo haitiano, francês, japonês e italiano foram também citadas pelos participantes. No que tange à circulação dessas línguas, em Foz do Iguaçu é notória, por exemplo, a presença de comunidades de imigrantes de diversas origens e filiações étnicas (árabes, asiáticos, europeus, latino-americanos de diversos países da América do Sul e Caribe), o que se verifica também na paisagem linguística do município, como já apontaram diversos trabalhos acadêmicos, como os de Ribeiro (2007) e Silva et al. (2016). Dada essa realidade, visamos mapear se essas línguas de algum modo compunham o repertório linguístico dos participantes, o que, de fato se constatou, conforme podemos visualizar na Tabela 1. No que se refere às línguas alemã e italiana (e suas variedades), há que se ressaltar a contribuição de comunidades teuto e ítalo-brasileiras no Estado do Paraná em seus aspectos culturais, sociais e econômicos.

No que se refere à língua crioulo haitiano, a presença de um numeroso grupo de haitianos no município é igualmente expressiva, principalmente considerando as políticas educacionais da UNILA que divulga editais específicos para o ingresso de alunos haitianos residentes no Brasil em seus cursos de graduação. A presença desse público no cenário multilíngue de Foz do Iguaçu e região da fronteira vem contribuindo para ampliar a circulação de línguas como o crioulo haitiano e o francês nesse espaço, impactando nas dinâmicas sociais locais. Nos dados qualitativos, um dos participantes indicou conhecimento de crioulo haitiano. Sobre a questão da presença dessa língua nos espaços de escolarização da região, podemos mencionar os efeitos desse recente movimento migratório nas escolas, que precisam romper o véu monolíngue para lidar com a presença de alunos migrantes em suas práticas linguísticas e culturais. Essa é discussão aprofundada por Lunardelli e Santos (2020) a partir de estudo de caso desenvolvido sobre a gestão das línguas na escola, como efeito do ingresso de haitianos nos espaços de escolarização de Medianeira, PR.

Ainda em relação aos impactos dessa comunidade na região, embora os haitianos sejam em grande medida falantes de francês, uma vez que se trata de língua oficial daquele país, os dados não nos permitiram relacionar o quantitativo da menção à língua francesa a esse grupo em específico. Os conhecimentos de língua francesa, declarados pelos participantes, são relacionados principalmente a insumos recebidos por meio de cursos livres, filmes, viagens e mídias em geral e tendo como referência linguística e cultural a França. Esse dado nos oferece indícios de atitudes linguísticas de alguns dos participantes em relação à dada variedade da língua, como ideal de cultura como sofisticação, conforme pudemos ler no comentário: "Acho francês lindo e chique."

A vista do que expomos no parágrafo anterior, de modo a elucidar os dados quantitativos, propusemos uma questão visando obter elementos sobre as trajetórias de ensino-aprendizagem e aquisição de línguas dos participantes, antes do ingresso na universidade. Verificamos, com isso, que parte das línguas listadas foram aprendidas em cursos livres, ensino básico e/ou superior prévio à formação em Letras. Os participantes da pesquisa declararam ter 
tido aulas de várias dessas línguas em cursos livres ou em graduações anteriores e, também, declaram possuir conhecimentos em nível básico. Além disso, muitos declararam ter aprendido as línguas em ambientes extraescolares, no cotidiano das interações, bem como por meio de mídias como jornais, internet, jogos, televisão, etc. Isso evidencia o dinamismo das relações dos participantes com as línguas, que extrapola o espaço de sala de aula. Citamos, portanto, alguns dos comentários que se sobressaíram durante a leitura dos dados qualitativos:

P9: "[...] tenho vizinhos indianos que falam inglês, às vezes me comunico com eles, é bom para praticar e aprender."

Pı: "Reforço o que estou aprendendo de inglês através de filmes e aprendendo algumas noções de japonês e coreano através de filmes e aplicativos da internet."

P11: "Utilizo as mídias para aprimorar o meu espanhol. Configuro meu celular e aparelhos eletrônicos para o espanhol, assim como minhas páginas virtuais."

O comentário de P9 corrobora a afirmação de que, do ponto de vista linguístico-cultural, Foz do Iguaçu se caracteriza por ser um espaço plural em que residem muitos grupos de imigrantes de diferentes origens. E, no que tange aos comentários de P10 e P11, verificamos que as mídias desempenham papel importante na aprendizagem de diferentes línguas pelos participantes, tanto no que diz respeito às línguas ofertadas pelo curso, como a outras línguas, como é o caso do japonês e coreano.

Prosseguindo com a análise, questionamos aos participantes que língua(s) consideravam sua(s) primeira(s) línguas(s) e por quê. A pergunta proposta teve como pressuposto o de que, em ambientes multi/plurilíngues, podemos desenvolver repertórios plurais desde a primeira infância, dependendo da situação de contato com as línguas no domínio familiar e comunidade. Dito de outro modo, reiteramos a concepção de que sujeitos bilíngues são aqueles que possuem experiências diversas e incomparáveis com cada uma das línguas que compõem seus repertórios (GARCÍA,2009). Por essa razão, compreendemos que a primeira língua (aqui entendida também como língua materna) pode ser uma ou mais, a depender das condições a que os participantes foram expostos às línguas na primeira infância. $\mathrm{O}$ gráfico a seguir apresenta os resultados. 
Gráfico 1: Línguas declaradas como primeira(s) língua(s)

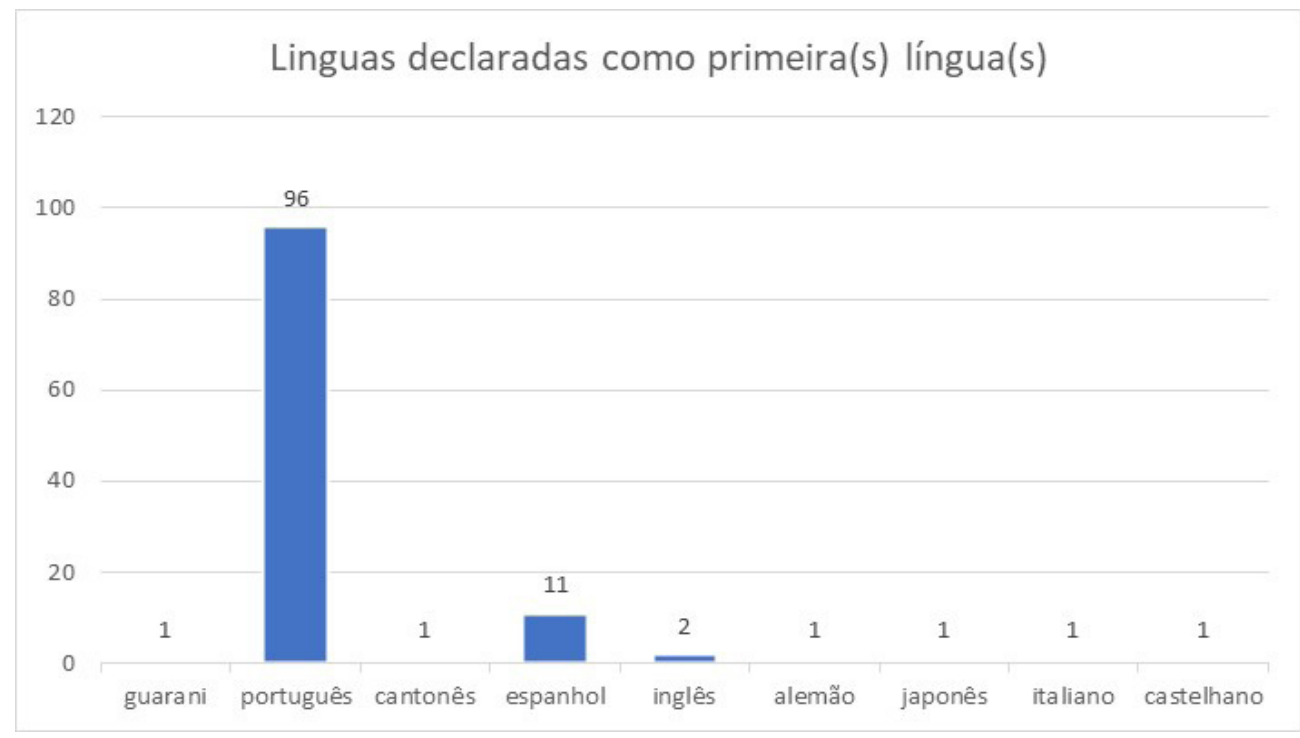

Fonte: Dados da pesquisa. Elaboração dos autores.

Com o total de 96 (noventa e seis) respostas, a língua portuguesa foi majoritariamente declarada como primeira língua. Os dados qualitativos nos indicam que, em sua maioria, os indivíduos afirmaram ter sido expostos somente à língua portuguesa quando crianças, inicialmente no domínio familiar e, posteriormente, no domínio da escola durante a fase de alfabetização/letramento. Essa informação chamou-nos atenção, pelo fato de a maioria ser residente nessa região de fronteira, onde a circulação de línguas é uma constante. Nesse sentido, supomos que, devido à orientação monolíngue que esteve no centro das políticas linguísticas do país (OLIVEIRA; ALTENHOFEN, 2011), a percepção em relação à realidade multilíngue pode não ter se dado em um primeiro momento no processo de socialização e, portanto, não reforçada no domínio familiar, como parte da gestão de línguas da família (SPOLSKY, 2009).

Dentre os participantes que indicaram a língua portuguesa para essa questão, 7 (sete) deles declararam ter como primeira língua também o espanhol, concomitantemente, e I (um) participante declarou que suas primeiras línguas são o português e o japonês. Outros 4 (quatro) participantes declaram como primeira língua o espanhol, tão somente. Um dos participantes também declarou o castelhano como primeira língua, juntamente com guarani e português. Os idiomas inglês, alemão, cantonês e italiano foram citados para esta questão, porém, sem maiores informações.

Destacamos a seguir, algumas das justificativas apresentadas pelos participantes de acordo com a escolha que fizeram em relação às suas primeira(s) língua(s).

P12: "Português, porque é a minha língua materna, que eu aprendi quando criança." 
P13: "Português e Japonês porque desde pequena, meus pais falavam comigo em japonês em casa."

P14: "Português, pois é a primeira língua com que tive contato, é a língua na qual organizo meu pensamento."

P15: "Português, foi a primeira língua que fui exposto por muito tempo."

P16: "O português porque nasci num país que fala nesse idioma e meus pais o utilizam para se comunicar"

P17: "Português brasileiro, pois nasci no Brasil e vivi somente com falantes dessa língua."

P18: "A minha primeira língua é a língua Guarani, porque nessa língua que meu país me ensinou a falar, é a língua que aprendi primeiro.”

P19: "Espanhol, porque nasci onde se fala esse idioma e morei por um tempo, e falo em casa."

Conforme podemos verificar, as justificativas para atribuir a uma ou mais línguas o lugar de primeira língua no repertório linguístico dos participantes parte de diferentes perspectivas. Para P12 e P13, a primeira língua é aquela aprendida na infância, no contato com familiares. O comentário de P14, por sua vez, relaciona a primeira língua está a aspectos de ordem cognitiva em que a primeira língua é aquela que permite a organização do pensamento. Para P15, a primeira língua está vinculada ao tempo de exposição ao idioma. E, por fim, para os demais, a primeira língua também se vincula ao país de nascimento e, portanto, podemos inferir de que os comentários carregam um sentido simbólico, de filiação a uma identidade nacional, em que a língua se constitui como um de seus elementos representativos.

Visando aprofundar o conhecimento sobre o perfil linguístico dos participantes, no sentido de compreender a formação de seus repertórios, buscamos identificar também as línguas faladas no ambiente doméstico pelos acadêmicos. A família se constitui como um importante domínio de gestão de línguas (SPOLSKY, 2009), pois é nele que se reforçam ou não atitudes e valores atribuídos às línguas que compõem a ecologia de línguas do entorno social, bem como é onde podem ser adotadas estratégias para a manutenção de línguas e transmissão intergeracional daquelas que se constituem como herança familiar. À vista dessa assunção, verificamos que os dados sugerem que a pluralidade que configura o ambiente sociolinguístico de Foz do Iguaçu e região se projeta nos lares de alguns desses professores em formação. 
Gráfico 2: Línguas faladas pelos participantes em casa

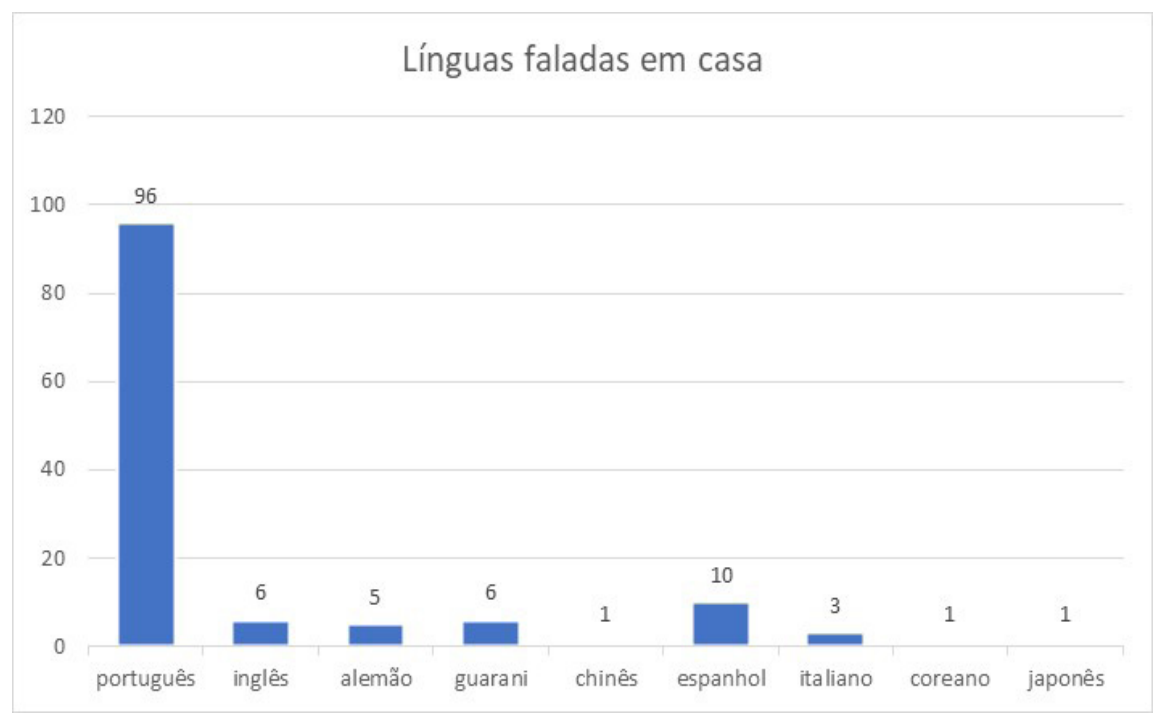

Fonte: Dados da pesquisa. Elaboração dos autores.

Os números indicam que o espanhol (declarado por 10 participantes) é possivelmente a segunda língua mais falada no ambiente doméstico. Verificamos, também, que os participantes se comunicam em outras línguas em seus lares, o que nos leva a concluir que no domínio da família há práticas linguísticas bi/plurilíngues, em que línguas (ou elementos de línguas) como alemão, guarani, chinês, espanhol, italiano, coreano e japonês são, possivelmente, usadas ao lado da língua portuguesa. Trata-se do que García (2009) define como translinguagem, que considera que a partir de experiências diversas e incomparáveis com cada uma das línguas ou elementos linguísticos que compõem os repertórios linguísticos dos sujeitos bi/plurilíngues, esses possuem uma habilidade para usar as línguas de forma diferenciada selecionando estrategicamente, e de modo flexível, línguas ou elementos de seus repertórios para se comunicarem. Destacamos o comentário de um dos participantes que corrobora essa afirmação:

P20: "Eu admito que com meus pais eu converso numa mistura de 4 línguas. (português, espanhol, inglês, guarani).

Passamos agora a observar outro aspecto que nos foi foco de análise e que diz respeito à questão da identificação linguística em meio à pluralidade desse contexto. Partimos do pressuposto de que um questionamento sobre as línguas com as quais os participantes mais de identificavam poderia fornecer-nos indícios de suas atitudes diante das línguas que configuram esse espaço plural e de suas relações com aquelas que compõem seus repertórios linguísticos. Sobre esse tema, volvemos à afirmação constante em Ribeiro (2007, p. 39): "Identificar-se com uma língua ou uma variedade linguística é antes querer fazer parte e tomar para si um ideal social formado pela tradição, pelos padrões determinados e convencionados como mais prestigiosos e adequados". 
Assim, diante dessas considerações, no gráfico a seguir apresentamos os dados relativos à questão: "Com qual(quais) língua(s) você mais se identifica? Por quê?”

Gráfico 3: Línguas com as quais os participantes mais se identificam

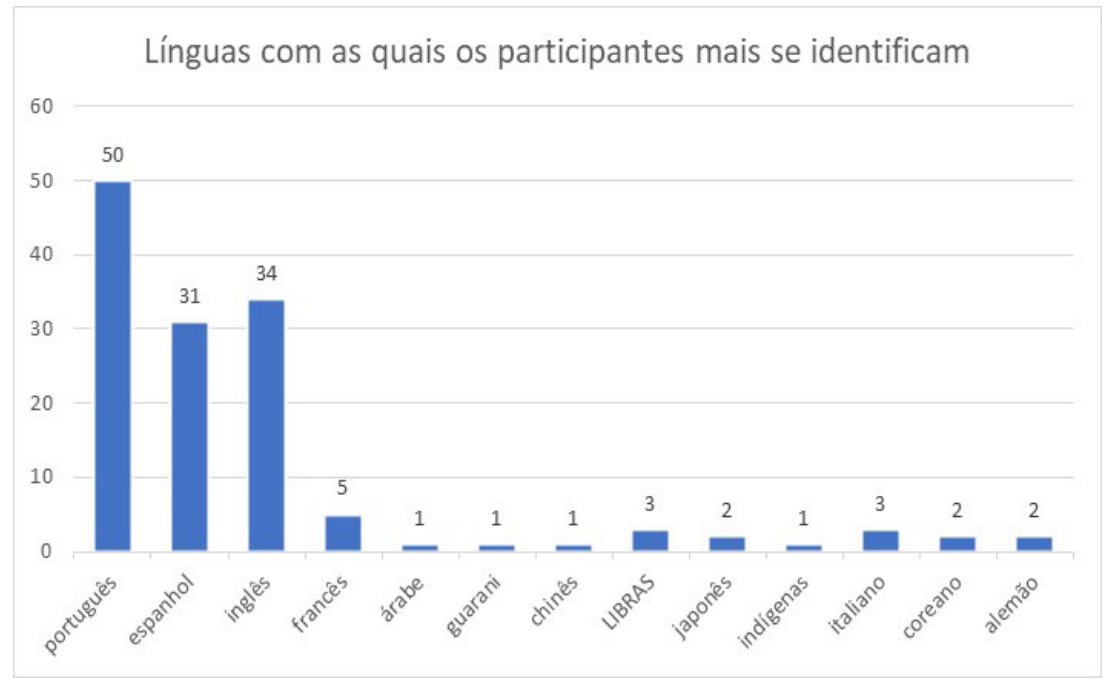

Fonte: Dados da pesquisa. Elaboração dos autores.

Por meio de análise quantitativa, identificamos que exatamente a metade dos participantes da pesquisa declararam se identificar com a língua portuguesa. Considerando que, como a maioria dos participantes são brasileiros, tendo a língua portuguesa como primeiro idioma de interação social, inferimos que a escolha por esse número de participantes se vincula a um possível sentimento de pertencimento e de formação de identidade individual e coletiva, conforme apresentaremos em comentários mais adiante. Nesse sentido, Rajagopalan (1998, p. 41) afirma que: "[...] a identidade de um indivíduo se constrói na língua e através dela. Isso significa que o indivíduo não tem uma identidade fixa anterior e fora da língua.”. Com isso, podemos afirmar que as línguas se constituem como importante elemento de construção de identidades e marcadores de diferenças, que se consolidam nos processos de socialização e que são inerentes às culturas.

Também inglês e espanhol foram as línguas mais indicadas para essa questão, sendo 34 (trinta e quatro) e 31(trinta e um) as quantidades obtidas para cada uma dessas línguas, respectivamente. Inferimos que essa identificação com uma língua diferente da língua materna possa estar relacionada às atitudes desses participantes em relação a essas línguas, além de ser um fator de motivação para cursarem a graduação em Letras, com habilitação nas mesmas.

Quanto às várias razões que os participantes apontaram como decisivas na identificação com certas línguas estão: a relação com a primeira língua; suas preferências (gosto pessoal) por músicas, séries e mídias em geral nessas línguas; suas conexões com familiares falantes de algumas dessas línguas; relações de afeto e sentimentos que as línguas evocam; bem como 
interesses por aspectos culturais relacionados à realidade sócio-histórica e cultural das três fronteiras. A seguir, destacamos alguns dos comentários dos participantes que pautam essas análises:

P21: "Português, pois a primeira língua com que tive contato, é a língua na qual organizo meu pensamento."

P22: "O espanhol porque é a minha língua materna. Não posso dizer o mesmo de outras línguas, já que não tive contato com elas desde cedo."

P23: "Com a língua guarani, porque é minha língua, com ela eu penso e interpreto as coisas."

P24: "Italiano porque meu pai é descendente e alemão por parte da minha mãe."

P25: "O chinês me dá a sensação de conexão com a minha família"

P26: "Alemão e inglês, porque gosto da estrutura das línguas germânicas e, também, me interesso pela cultura. No caso do Alemão, há o componente de herança.

P27: "Inglês, pois todos os tipos de mídia (artigos, apps, livros, series) que são de minha preferência estão em inglês."

P28: "Espanhol representa el lugar donde vengo. [Paraguai]."

P29: "Espanhol/Castelhano pois meus avós eram paraguaios e eu acho um idioma muito bonito e, também, por maior contato em viagens na América do sul."

P30: "Espanhol, gosto do idioma e em área de fronteira o contato com falantes dessa língua é inevitável."

P31: "Espanhol, por conta da "proximidade" com o português. A identificação vem da necessidade por se tratar de uma área de fronteira, e pelo fato do BR estar cercado de países falantes de Espanhol.”

Desses comentários sobressaem as relações que os participantes possuem com suas primeiras línguas (P21, P22, P23), suas relações com línguas que compõem histórias familiares e relações de afeto com as heranças e memórias que algumas das línguas resguardam (P24, P25, P26), identificação com aspectos culturais relacionados a algumas das línguas (P26, P27) e, por fim, sentimento de pertencimento ao espaço fronteiriço de encontro com países hispano-falantes (P28, P29, P30, P31). Assim, podemos afirmar, a partir de Ribeiro (2007) que a identidade linguística está diretamente relacionada a representações, pois identificar-se com uma língua ou variedade é tomar para si um ideal social formado por tradição, por padrões e convenções tidas como mais prestigiosas ou adequadas.

Por fim, passamos a apresentar os dados relativos às línguas que os participantes declararam ter interesse em aprender. Para essa questão, tivemos como objetivo depreender possíveis atitudes em relação a línguas que caracterizam o mosaico linguístico e cultural da 
região. Assim, partimos do pressuposto de que a questão poderia revelar representações e valores atribuídos às línguas e comunidades linguísticas e de fala que estão em situação de contato e interação nessa região de fronteira.

Identificamos que, em posição de relativa igualdade, os participantes destacaram a língua francesa (28), a língua inglesa (23) e a língua italiana (23) entre suas principais preferências. Línguas como guarani e alemão foram citadas como aquelas que se relacionam ao ambiente familiar, tradições e identificação cultural. A relação dos participantes com essas línguas estava estritamente vinculada a questões de ordem afetiva e com línguas que representam heranças e culturas familiares, conforme já pontuamos nas análises anteriores. Nesse sentido, vale ressaltar que, o caso da menção ao alemão é representativo de uma comunidade de línguas de imigração tradicionais na região, a exemplo do ambiente sociolinguístico de Marechal Cândido Rondon, um dos municípios dessa região de fronteira em que a universidade possui um de seus campi (REDEL; MARTINY, 2016).

Outras línguas citadas nos comentários tinham, para os participantes que as escolheram, um apelo de curiosidade e até de exotismo. Ainda, outros motivos apontados para o desejo de aprender diferentes línguas vão desde interesse por questões culturais até expectativas de melhores oportunidades no mercado de trabalho. No caso de LIBRAS, um número pequeno de participantes fez menção à língua, externando uma sensibilização diante da comunidade surda em suas demandas e direitos linguísticos. Vejamos alguns dos comentários:

P32: "Gostaria de aprender mais o francês porque acho uma língua muito rica e bela."

P33: "Gostaria de aprender algumas línguas asiáticas como o japonês e o coreano, por pertencerem a uma cultura muito diferente e não serem parecidas com o português."

P34: "Alemão; Sueco; Norueguês; Islandês. Porque gosto das línguas germânicas."

P35: "Inglês, por causa da demanda no mercado de trabalho."

P36: "Gostaria de ter aprendido o guarani com meus avós, o motivo é o valor afetivo, minha mãe fala mas não nos ensinou em casa."

P37: "Gostaria de aprender Italiano. Porque convivo com falas na língua em reuniões familiares e seria uma forma de conhecer minhas origens." P38: "Eu gostaria de aprender, de fato, alemão, pois minha família materna fala, na maioria das vezes, em alemão."

P39: "LIBRAS, porque acredito que é necessário que aprendamos a nos comunicar com os surdos.”

P40: "Quero muito ser fluente em LIBRAS, para poder me comunicar com a comunidade surda, tão presente aqui em Foz."

P41: “[...] LIBRAS por motivo de inclusão.” 
Os comentários nos apresentam um panorama das atitudes que emergem desse ambiente multi/plurilíngue, dos quais é possível depreender valores culturais, simbólicos, econômicos e/ou educacionais atribuídos às línguas mencionadas pelos participantes. Conforme Ribeiro (2007), a motivação para aprendizagem de uma língua pode estar relacionada com as atitudes diante dela, ou seja, a comunhão de representações e sentimentos diante de línguas diversas.

Passamos, portanto, às considerações finais.

\section{CONSIDERAÇõES FINAIS}

A pesquisa apresentada neste texto tematizou o multilinguismo nos espaços de sala de aula e, como objetivo específico, visamos conhecer e refletir sobre o perfil linguístico de professores de línguas em formação e suas relações com as línguas do ambiente sociolinguístico multi/plurilíngue de fronteira em que realizam seu curso de formação inicial em Letras. Para tanto, a investigação foi norteada pelos objetivos de conhecer os repertórios linguísticos dos professores em formação, bem como depreender e refletir sobre a relação desses professores em formação diante de línguas da comunidade e do entorno social, bem como de outras línguas mencionadas por eles no instrumento de pesquisa.

Os dados apontaram para a existência de um alunado com perfil linguístico bastante heterogêneo que espelha, de muitos modos, o espaço plural em que se situa a instituição de ensino. As oportunidades de interação com falantes bi/plurilíngues na região, as várias histórias entre línguas e culturas que solidificam relações de afeto e identidades, além do compartilhamento das múltiplas percepções sobre as línguas que configuram seus repertórios pessoais, propiciaram-nos conhecer o solo em que se assenta a formação do profissional de Letras dessa região. E, sobre isso, de acordo com a política linguística da instituição, o estudo vai ao encontro do objetivo constante do documento que é o de "[...] conscientizá-lo [o discente] da heterogeneidade contextual, social, cultural e histórica [desse ambiente linguístico].” (UNIOESTE, 2018, p. 2-3).

Embora nem todas as línguas constantes do mosaico linguístico-cultural da região tenham sobressaído nos dados, a exemplo da língua árabe que é representativa de uma das comunidades linguísticas mais expressivas da região e da língua ucraniana, cuja comunidade de fala também se encontra no município em menor proporção, evidenciamos aqui uma possibilidade de aprofundamento do estudo, tanto no que diz respeito à percepção dessas línguas, quanto no que tange às suas atitudes diante delas e de seus falantes.

A investigação esteve alicerçada em estudos sobre políticas linguísticas para o multilinguismo, precisamente no que tange aos desafios existentes no domínio da escola (e universidade) para gerir a pluralidade de línguas diante de políticas linguístico-educacionais que foram 
construídas a partir de uma orientação monolíngue e de compreensão do multilinguismo como um problema do ponto de vista de sua gestão. Nesse sentido, concordamos com o argumento de Broch (2014, p. 230) de que "Isso significa que a entrada de uma língua no contexto escolar não deve ser vista como uma ameaça as línguas existentes, mas como um acréscimo a uma competência única, porém plural."

Nosso pressuposto, portanto, é a de que professores de línguas (em formação e exercício) precisam conhecer e, em sua prática, necessariamente, agir diante de fenômenos que emergem de contextos plurais em espaços de escolarização. Para tanto, compreendemos que se faz necessário criar estratégias para subsidiar reflexões em torno do tema na universidade, espaço em que se dá a formação inicial. Isso posto, reiteramos o argumento de que:

Ao não se contemplar a diversidade linguística como parte essencial e indispensável à formação de professores, precisamente nos dias de hoje, em que os fluxos migratórios levam a configurações demográficas plurais no âmbito dos países, estados e cidades, corre-se o risco de formar professores para atuarem em um mundo uniforme e homogêneo que não existe. (BERGER, 2015, p. 157).

A metodologia adotada para a realização dessa pesquisa constitui-se, em si, como um instrumento de reflexão entre os participantes, uma vez que foram levados a pensar sobre seus repertórios linguísticos e sobre as formas como se relacionavam com as línguas do entorno social, com as línguas que constituíam suas histórias pessoais de aquisição e aprendizagem, e com aquelas que traduziam memórias e relações familiares. Nesse sentido, o mapeamento linguístico escolar cumpre uma função político-linguística de levar à percepção sobre fenômenos que emergem de contextos multi/plurilíngues e de sensibilização quanto ao bi/multilinguismo tanto individual quanto social. Com isso, compartilhamos da expectativa de Heck et al. (2020, p. 135) de que a pesquisa contribua para "[...] maximizar o ensino e o processo de aprendizagem, auxiliando os graduandos em discussões enriquecedoras sobre políticas linguísticas, plurilinguismo e formação docente para lidar com a diversidade linguística".

\section{Agradecimentos}

Agradecimentos à Fundação Araucária pela Bolsa de Iniciação Científica, concedida no âmbito da Unioeste, para realização de parte dessa investigação.

Agradecemos, também, ao Prof. Dr. Luciano Marcos dos Santos pelas valiosas contribuições durante a finalização da pesquisa. 


\section{REFERÊNCIAS}

BERGER, I. R. Gestão do multi/plurilinguismo em escolas brasileiras na fronteira Brasil Paraguai: um olhar a partir do Observatório da Educação na Fronteira. Tese (Doutorado em Linguística). Programa de Pós-Graduação em Linguística, Universidade Federal de Santa Catarina, Florianópolis, 2015.

BERGER, I. R. Estudos em atitudes e políticas linguísticas: percursos entre fronteiras geográficas, políticas e linguísticas. In: Ideação, v. 22, n. 2, 2020, p. 4-9.

BROCH, I. K. Ações de promoção da pluralidade linguística em contextos escolares. Tese (Doutorado) - Universidade Federal do Rio Grande do Sul, Porto Alegre, 2014.

CALVET, L. J. Sociolinguística: uma introdução crítica. São Paulo: Parábola Editorial, 2002.

FRAGA, L. Políticas Linguísticas na formação do licenciado em Letras: uma discussão introdutória. In: CORREA, D. A. (org.) Política Linguística e Ensino de Língua. Campinas, SP: Pontes Editores, 2014.

GARCÍA, O. E., multilingualism and translanguaging in the 21st century. In: MOHANTY, A. et.al (Ed.). Multilingual Education for Social Justice: globalising the local. New Delhi: Orient Blackswan (former Orient Longman), 2009.

GIL. A. C. Métodos e Técnicas de Pesquisa Social. 6 ed. São Paulo: Editora Atlas. 2011.

HECK, D. M.; REDEL, E.; MARTINY, F. M. Interfaces entre as políticas linguísticas e a formação docente: crenças e expectativas de estudantes de Letras. In: BERGER, I. R.; REDEL, E. (Orgs.) Políticas de gestão do multilinguismo: práticas e debates. Campinas, SP: Pontes Editores, 2020. p.

LUNARDELLI, M.G.; SANTOS, R.A.B. Rompendo o véu monolíngue: caminhos possíveis de gestão de línguas no Ensino Fundamental em Medianeira, PR. In: BERGER, I. R.; REDEL, E. (Orgs.) Políticas de gestão do multilinguismo: práticas e debates. Campinas, SP: Pontes Editores, 2020. p.

MENKEN, K.; GARCÍA, O. Negotiating Language Policies in Schools: educators as policymakers. New York: Routledge, 2010.

OLIVEIRA, G. M.; ALTENHOFEN, C. V. O in vitro e o in vivo na política da diversidade linguística no Brasil: inserção e exclusão do plurilinguismo na educação e na sociedade. In: MELLO, H.; ALTENHOFEN, C.V.; RASO, T. (Org.). Os contatos linguísticos no Brasil. Belo Horizonte: Editora UFMG, 2011.

OLIVEIRA, G.M. Declaração Universal dos Direitos Linguísticos: novas perspectivas em Política Linguística.Campinas, SP: Mercado das Letras, Associação de Leitura do Brasil (ALB); Florianópolis: IPOL, 2003. 
OLIVEIRA, G.M. O lugar das línguas: A América do Sul e os mercados linguísticos na Nova Economia. Synergies Brésil n spécial 1 - 2010 pp. 21-30

OLIVEIRA, G.M. Plurilinguismo no Brasil: repressão e resistência linguística. In: Synergies Brésil. [S.l.], v. 1, p. 19-26, 2009.

RAJAGOPALAN. K. O conceito de identidade em linguística: é chegada a hora para uma reconsideração radical? In: SIGNORINI, I. (Org.) Lingua(gem) e identidade: elementos para uma discussão no campo aplicado. Campinas, SP: Mercado das Letras; São Paulo: Fapesp, 1998, p. 21-45.

REDEL, E.; MARTINY, F. M. Performance humorística: a produção de um estereótipo de falante alemão-rondonense. Calidoscópio. V. 14, n. 2, p. 199-208, mai/ago 2016.

RIBEIRO, I. Atitudes linguísticas e aprendizagem de línguas: um estudo de caso em Foz do Iguaçu. Dissertação (Mestrado em Letras) - Universidade Estadual do Oeste do Paraná, 2007.

SANTOS, L. M. Atitudes linguísticas de trabalhadores de Ciudad del Este quanto ao jopará no Jornal Diario Popular. Ideação, v. 22, n. 2 (2020), p. 60-82.

SAVEDRA, M. M. G. Bilinguismo e bilingualidade: uma nova proposta conceitual. In: SAVEDRA, M.M.G.; SALGADO, A.C.P (Orgs.) Sociolinguística no Brasil: uma contribuição dos estudos sobre línguas em/de contato. 1. ed. Rio de Janeiro: 7Letras: 2009. p. 121-140.

SEIFFERT, A. P. Censo, diagnóstico, inventário e observatório linguísticos: aspectos metodológicos e papel político-linguístico. 2014. Tese (Doutorado) - Universidade Federal de Santa Catarina, Centro de Comunicação e Expressão. Programa de Pós-Graduação em Linguística, Florianópolis, 2014.

SILVA, I.; PIRES-SANTOS, M.E.; JUNG, N. M. Multilinguismo e política linguística: análise de uma paisagem linguística transfronteiriça. Domínios da Linguagem. v. 10 n.4 | out./dez. 2016, p. 1257-1277.

SPOLSKY, B. Language Management. NY: Cambridge University Press, 2009.

UNESCO. 2021 International Mother Language Day: Fostering multilingualism for inclusion in Education and Society. 2021. Disponível em: https:/en.unesco.org/sites/default/files/ imld_2021_concept_note_en.pdf. Acesso em: 10 fev. 2021.

UNESCO. Multilingualism in focus at UNESCO International Literacy Day conference. 2019. Disponível em: https:/en.unesco.org/news/multilingualism-focus-unesco-internationalliteracy-day-conference. Acesso em: 10 mar. 2021.

UNIOESTE. Política Linguística Institucional da UNIOESTE. Resolução No $002 / 2018-C E P E$, de 12 de abril de 2018. Universidade Estadual do Oeste do Paraná, Cascavel, 2018. 